\title{
A New Methodology for Monitoring the Activity of cdMMP-12 Anchored and Freeze-dried on $\mathrm{Au}(111)$
}

\author{
Giuseppe Grasso \\ Consorzio Interuniversitario di Ricerca in Chimica dei Metalli nei Sistemi Biologici, Bari, Italy
}

Marco Fragai

Magnetic Resonance Center (CERM), University of Florence, Sesto Fiorentino, Italy

Enrico Rizzarelli and Giuseppe Spoto

Dipartimento di Scienze Chimiche, Università di Catania, Catania, Italy

\author{
Kwon Joo Yeo \\ Magnetic Resonance Center (CERM), University of Florence, Sesto Fiorentino, Italy
}

\begin{abstract}
Matrix metalloproteinases (MMPs) are cell-secreted soluble and membrane-tethered enzymes that are capable of degrading extracellular matrix proteins, but also can process a number of bioactive molecules. They are involved in the cleavage of cell surface receptors, but are also thought to play a major role on cell behaviors as well as in diverse physiological and pathological processes, including embryonic development, wound repair, inflammatory diseases, and cancer. For these reasons, it is obvious that a control over MMPs activity is highly desirable. Consequently, the frantic search for new inhibitors has been coupled to the development of high-throughput methods able to rapidly screen the effect of possible MMP inhibitors on the activity of these enzymes. In this scenario, solid-state-based methods play a major role because of their compatibility with array formats that are able to extract more information from smaller sample volumes and offer some important advantages that are not available in the standard solution assays. In this work, the catalytic domain of MMP-12 was immobilized on a gold substrate and the surface coverage was measured by FT-SPR experiments. A new experimental procedure was developed to freeze-dry the anchored molecules and their activity was measured by ESI-MS. The kinetics parameters obtained for the immobilized enzyme are in good accordance with those reported for similar systems in solution. Inhibition of the immobilized molecules was also carried out, demonstrating the applicability of the method for rapid screening of MMP inhibitors. (J Am Soc Mass Spectrom 2007, 18, 961-969) (C) 2007 American Society for Mass Spectrometry
\end{abstract}

$\mathrm{R}$ ecent advances in enzyme engineering and discovery have created new demands for methods aimed at rapid and reliable evaluation of enzymatic activities as well as chemical screening of enzyme inhibitors [1]. In particular, a number of recent papers have highlighted advantages offered by assays that use solid-state supports and are compatible with array formats [2-4]. Such formats extract more information from smaller sample volumes [5] and offer some important advantages that are not available in the standard solution assays such as $i$ ) the possibility to recycle the studied enzymes; ii) a tag-free working environment

Published online March 28, 2007

Address reprint requests to Prof. Giuseppe Spoto, Dipartimento di Scienze Chimiche, Università di Catania, Viale Andrea Doria 6, 95125, Catania, Italy. E-mail: gspoto@dipchi.unict.it that allows simple and rapid on-spot protein profiling [6]; iii) rapid throughput [7]; iv) improved discovery of protein binding partners through protein-affinity interactions [8]; and, most important, v) a multiplexed approach for the investigation of enzymes, allowing the coupling of different techniques such as, for instance, surface plasmon resonance (SPR) and mass spectrometry (MS) $[9,10,11]$.

Matrix metalloproteinases (MMPs) [12] are a family of zinc-dependent endopeptidases that play a fundamental role in normal and pathological processes, including embryogenesis, wound healing, inflammation, arthritis, and cancer [13, 14]. It is clear today that while in vivo the degrading actions of MMPs are limited by the tissue inhibitors of metalloproteinase (TIMP) family of natural macromolecular inhibitors, in diseases such as cancer MMPs are often overexpressed [15]. For this 
reason, only very recently, a huge effort has been put toward the development of inhibitors able to selectively target MMPs for therapeutic intervention in a variety of pathological events $[16,17]$. The ability to monitor MMP activity plays a pivotal role in the search for possible drugs [18] and the development of new solidstate assays for a rapid evaluation of MMPs activity is of great interest. MMP activity is mostly determined by using spectrophotometric assays [19, 20]. Such solutionbased methods suffer from inconveniences such as the inner filter correction [21] and the impossibility of recycling the MMPs for different analysis. Moreover, they require a fluorescent tag to be present in the substrate.

Recently, a solid-phase assay for analysis of MMP activity has been proposed, although a fluorescence tag in the substrate was still necessary to detect the activity [22]. One of the techniques useful for detecting the activity of MMPs that does not need the presence of any fluorescent tag is electrospray ionization mass spectrometry (ESI-MS). The important contribution of mass spectrometric methods in the study of the structurefunction relationship of proteins and enzymes has recently drawn increasing interest by the scientific community [23-25], but problems related to the presence of buffer solutions, necessary when one has to deal with proteins, has limited this application of ESI-MS [26, 27], whereas matrix-assisted lased desorption (MALDI)-MS was considered appropriate for proteome analysis [28] and to be combined with biomolecular interaction analysis and SPR studies [29, 30].

A new strategy to identify general enzyme inhibitors and monitor enzyme activity by SPR combined with MS has been demonstrated [11], but every attempt to study MMPs by SPR has been carried out by anchoring the possible inhibitor and keeping the MMP molecules in the liquid phase [31,32]. Only very recently, a different procedure has been described [33], according to which it is possible to immobilize the human MMP-1 catalytic domain (cdMMP-1 hereafter) on Au (111). Activity of the immobilized cdMMP-1 was estimated by the use of ESI-MS and, although some kinetics parameters for such enzyme were obtained, the errors associated with those measurements were relatively high, mainly as a result of the difficulty in handling the gold surfaces after the enzyme immobilization. The main problem associated with the above-mentioned method was that the drying of the functionalized gold surface usually led to a loss of the enzyme activity. To avoid this, the initial peptide concentration on the surface was not easy to control because of the inevitable dilution occurring during the spotting process onto the wet surface. For the same reason, the volumes used (100 $\mu \mathrm{L}$ of solution for each peptide concentration) were not as small as desirable.

A method based on the in situ tryptic digestion and atmospheric pressure (AP) MALDI-MS analysis of MMPs immobilized on solid supports was also de- scribed [34], TMallowing ${ }^{\mathrm{T} T}$ the $\mathrm{T}^{\mathrm{T}}$ tharacterization ${ }^{\mathrm{T}} \mathrm{b} \mathrm{f}^{\mathrm{T} M M M P}$ arrays.

In this work we propose a new methodology for monitoring the activity of protein molecules anchored and freeze-dried on $\mathrm{Au}$ (111). The human MMP-12 catalytic domain (cdMMP-12 hereafter) was covalently immobilized on the Au (111) surface and freeze-dried by an experimental procedure that allows the enzyme to maintain its activity even in dry conditions. On the new functionalized surface many different peptide substrate solutions at different concentrations were applied, using a specially designed mask made of polydimethyl siloxane (PDMS) polymer and the activity of immobilized cdMMP-12 were measured by using a solid-state assay based on an ESI-MS approach.

\section{Experimental}

\section{cdMMP-12 Cloning and Purification}

The cDNA encoding the cdMMP-12 (Gly106-Gly263) was amplified by a polymerase chain reaction (PCR) from IMAGE consortium clone (ID 196612) using two synthetic oligonucleotides as primers. The cDNA obtained was cloned into the pET21a vector (Novagen) between the restriction sites NdeI and BamHI. The single amino acid substitution, to obtain the F171D mutant, was created using the QuickChange ${ }^{\mathrm{TM}}$ SiteDirected Mutagenesis Kit from Stratagene. The construct was transformed into the BL21Gold (DE3) strain for expression of recombinant protein. The cells were grown in $2 \times \mathrm{YT}$ media at $37^{\circ} \mathrm{C}$. The protein expression was induced during the exponential growth phase with $0.5 \mathrm{mM}$ IPTG (Isopropyl $\beta$-D-1-thiogalactopyranoside). Cells were harvested for $4 \mathrm{~h}$ after induction. After lysis of the cells the inclusion bodies, containing the protein, were solubilized in $8 \mathrm{M}$ urea and $20 \mathrm{mM}$ sodium acetate ( $\mathrm{pH}$ 5.0). The protein was purified on the Hitrap SP column (Pharmacia) with a buffer containing $6 \mathrm{M}$ urea and $20 \mathrm{mM}$ sodium acetate ( $\mathrm{pH}$ 5.0). The elution was performed using a linear gradient of $\mathrm{NaCl}$ up to $0.35 \mathrm{M}$. The purified protein was refolded by using a multistep dialysis against a solution containing $50 \mathrm{mM}$ Tris- $\mathrm{HCl}$ (pH 7.2), $10 \mathrm{mM} \mathrm{CaCl}_{2}, 0.1 \mathrm{mM} \mathrm{ZnCl}, 0.3 \mathrm{M} \mathrm{NaCl}, 500$ $\mathrm{mM}$ acetohydroxamic acid (AHA), and decreasing concentration of urea (from 4 to $2 \mathrm{M}$ ). The last two dialyses were performed against a solution containing $20 \mathrm{mM}$ Tris- $\mathrm{HCl}$ (pH 7.2), $5 \mathrm{mM} \mathrm{CaCl}_{2}, 0.1 \mathrm{mM} \mathrm{ZnCl}_{2}, 300 \mathrm{mM}$ $\mathrm{NaCl}$, and $500 \mathrm{mM}$ AHA. The refolded protein was concentrated up to $50 \mu \mathrm{M}$ using an Amicon stirrer and Centriprep concentrator, fitted with a YM10 membrane at $4{ }^{\circ} \mathrm{C}$.

\section{Immobilization of cdMMP-12 on Solid Support and Freeze-drying Procedure}

cdMMP-12 was anchored on Au (111) by using a two-step procedure. First, bare gold chips were incubated with dithiobis succinimidylpropionate (Lomant's 
Reagent) $[0.0097 \mathrm{~g}$ in $2 \mathrm{~mL}$ of Dimethyl Sulfoxide (DMSO), Sigma-Aldrich] for $48 \mathrm{~h}$ under inert athmosphere. The surface so treated was washed with pure DMSO and high-purity water (Milli-Q Element Ultrapure Water) and could react directly with cdMMP-12. $\mathrm{N}$-(2-Hydroxyethyl)piperazine- $\mathrm{N}^{\prime}$-(2-ethanesulfonic acid) $(60 \mu \mathrm{L})$ and sodium salt (0.01 M HEPES, $0.15 \mathrm{M}$ $\mathrm{NaCl}, \mathrm{pH}$ 7.4. HBS-N, Biacore International $\mathrm{AB}$ ) (HBS-N buffer hereafter) were mixed with the appropriate volume of protein mother solution to obtain a final concentration of $4.5 \mu \mathrm{M}$. This solution was then left in contact with the pre-functionalized gold surface for about $30 \mathrm{~min}$. After the anchorage of cdMMP12 , the substrate was washed with HBS-N buffer. This procedure provided a surface coverage of about $4 \times$ $10^{13}$ molecules $\mathrm{cm}^{-2}$ (determined by FT-SPR; see next paragraph). The HBS-N buffer has been verified to be the best buffer to be used to anchor the cdMMP-12 molecules to the gold surface, preserving their activity.

The freeze-drying procedure of the so functionalized gold surface cannot take place in such a buffer because the presence of salts on the dry surface would present problems in the following stage involving the adhesion of a PDMS mask to the gold surface. This is a necessary step to produce a surface arrayed with the holes that contain all the different peptide solutions in a controlled way. For this reason, the gold substrate was rapidly washed (about $3 \mathrm{~s}$ ) in high-purity water (Milli-Q Element Ultrapure Water) and then rapidly immersed in liquid nitrogen, while the surface was still wet with a layer of water. The chip with a layer of frozen water was located on top of an ice block inside a beaker. At this stage, the beaker with the frozen functionalized gold chip on top of the ice block was ready to be put in the freeze-dryer apparatus (LABCONCO), where it was left for about $12 \mathrm{~h}$. After the lyophilization process, the chip looked slightly opaque because of the presence of some residual salts on the surface. To have a totally shiny surface the rinsing with water has to be prolonged, but we found that the activity of the anchored enzyme is compromised in the case of an absolute salt-free surface. The presence of salts on the dry gold surface can be controlled by the time of the rinsing and $3 \mathrm{~s}$ was found to be an appropriate time to have the right amount of salts that preserves enzyme activity but does not hinder the adhesion of PDMS with the surface.

Immobilized enzyme activity assays were replicated on freeze-dried chips stored at $+4{ }^{\circ} \mathrm{C}$ for up to 2 weeks. No significant alteration of the cdMMP-12 activity was detected within this time interval.

PDMS film (1 mm thick) was obtained from a 1:10 mixture of PDMS curing agent and prepolymer (Sylgard 184, Dow Corning, Midland, MI, USA). The mixture was degassed under vacuum, poured onto a flat surface to create a layer with a thickness of about $1 \mathrm{~mm}$, and cured for at least $2 \mathrm{~h}$ at $60^{\circ} \mathrm{C}$. The PDMS film was then pierced to create an array of $2 \mathrm{~mm}$ in diameter holes. The obtained PDMS mask was then treated with

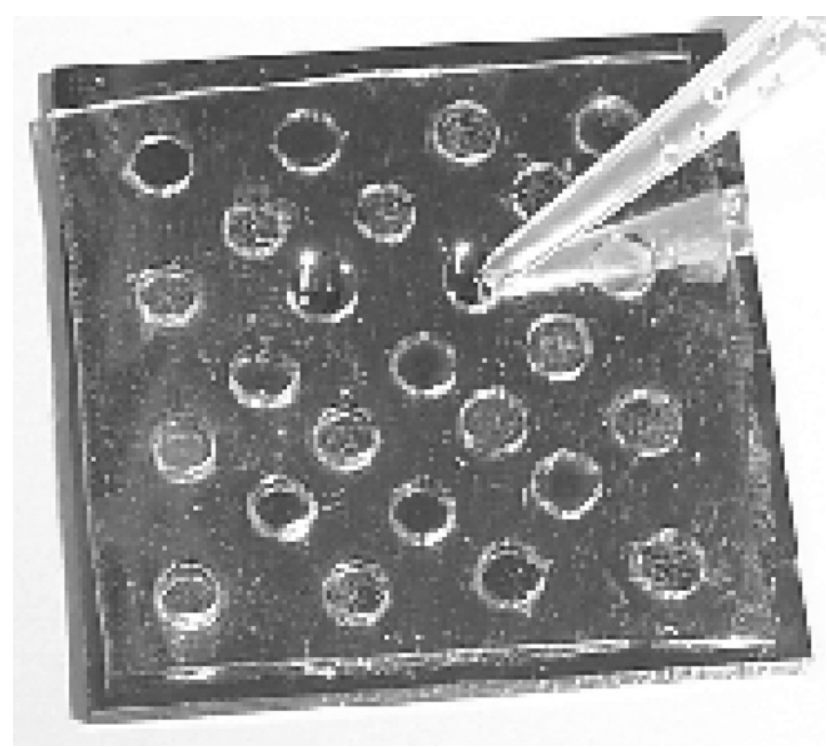

Figure 1. After the freeze-drying process a mask of PDMS is made to adhere to the gold surface. The amount of salts on the dry gold surface has to be accurately controlled: whereas a large amount on the dry surface makes the adhesion with the PDMS mask impossible, a too small amount of salts affects the activity of the anchored cdMMP-12, making the enzyme almost totally inactive. The figure shows the spotting process in one of the 25 arrayed holes, adjacent to another filled hole on the left side.

piranha solution (3:1 mixture of sulfuric acid and 30\% hydrogen peroxide) for $15 \mathrm{~s}$ to increase the wettability of its surface. This latter step allowed a perfect adhesion between the PDMS mask and the freeze-dried surface

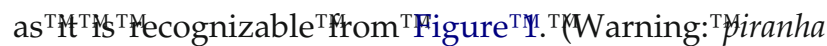
solutions should be handled with caution because they can detonate unexpectedly.)

The peptide substrate used to monitor the activity of cdMMP-12 (Biomol International, Philadelphia, PA, USA) is a known fluorogenic substrate for MMPs having the sequence Ac-Pro-Leu-Gly-[2-mercapto-4-methyl-pentanoyl]-Leu-Gly-OC ${ }_{2} \mathrm{H}_{5} \quad$ (P125 $^{\mathrm{TM}}$ hereafter $)^{\mathrm{TM}}[35]$, whereas N-Isobutyl-N-(4-methoxyphenylsulfonyl)glycyl hydroxamic acid (NNGH; Biomol International) was

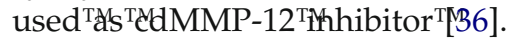

\section{Fourier Transform-Surface Plasmon Resonance (FT-SPR) Experiments}

FT-SPR experiments were carried out by using an FT-SPR 100 (GWC Technologies, Madison, WI, USA) apparatus. The light beam from an external port of a Nexus 870 FT-IR spectrometer (Nicolet, Madison, WI, USA), equipped with a quartz-halogen source and a $\mathrm{XT}-\mathrm{KBr}$ beam splitter, was used as the near-IR source of the FT-SPR. Gold substrates (GWC Technologies) were obtained by thermally evaporating a gold layer $(450 \AA)$ on to SF-10 glass slides (Schott, Elmsford, NY, USA). Chromium (50 ̊) was used as the adhesion layer. Gold substrates were brought into optical contact with the SF-10 equilateral prism present in the FT-SPR by using 


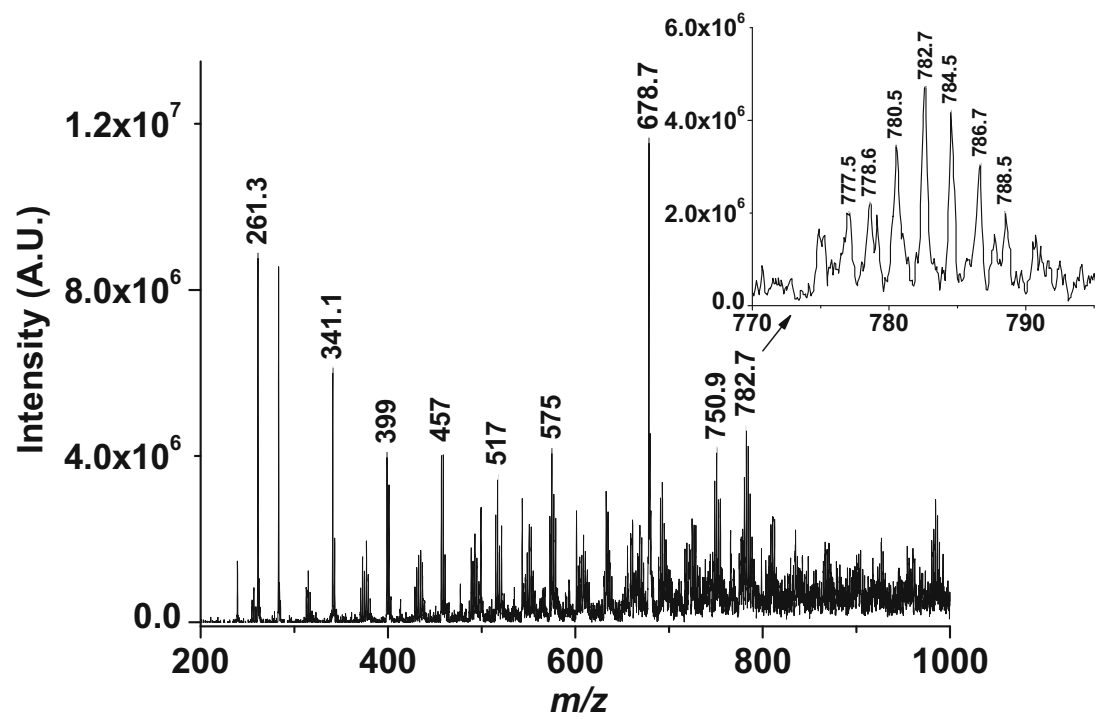

Figure 2. ESI-MS spectrum of P125 in HBS-N buffer. The peak at $\mathrm{m} / \mathrm{z} 678.7$ attributed to the monosodiated ion species is visible together with many other peaks generated from species present in the HBS-N buffer (see also Supplementary Material (which can be found in the electronic version of

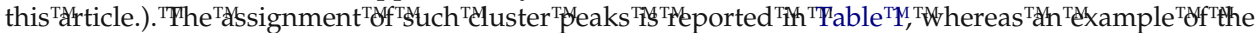
experimental isotopic abundance recorded for the cluster peaks generated by the $\mathrm{SO}_{3} \mathrm{H}(\mathrm{NaCl})_{12}$ species is also shown in the insert.

a refractive index matching fluid (Cargille Laboratories, Minneapolis, MN, USA). FT-SPR experiments were carried out by using a $60 \mu \mathrm{L}$ flow cell (GWC Technologies) and a Masterflex L/S (Cole-Parmer, Vernon Hills, IL, USA) peristaltic pump.

The FT-SPR sensor response was converted into refractive index changes by using independent sucrose aqueous calibrating solutions $\left(\mathrm{r}^{2}=0.999\right)$. The refractive indexes of the sucrose solutions were obtained

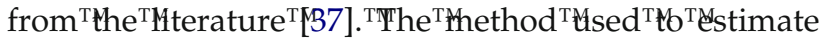
the number of cdMMP-12 molecules anchored on $1 \mathrm{~cm}^{2}$ of gold surface is already described elsewhere in detail $[33$, ,38 $]$.

\section{Electrospray Ionization Mass Spectrometry (ESI- MS) experiments}

All the ESI-MS measurements were carried out by using a Finnigan LCQ DECA XP PLUS ion trap spectrometer operating in the positive ion mode and equipped with an orthogonal ESI source (ThermoElectron Corporation, San Jose, CA, USA). Sample solutions were injected into the ion source at a flow-rate of $10 \mu \mathrm{L} \mathrm{min}{ }^{-1}$, using nitrogen as drying gas. The mass spectrometer operated with a capillary voltage of $46 \mathrm{~V}$ and a capillary temperature of $200{ }^{\circ} \mathrm{C}$, whereas the spray voltage was $4.3 \mathrm{kV}$.

The Xcalibur software was used for the elaboration of mass spectra and for the quantitative evaluation of the MS data.

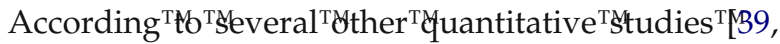

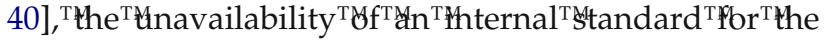
analysis can be overcome by the use of a calibration curve. To prepare stock standard solutions, 0.0006 gr. of
P125 were weighed and dissolved in $1 \mathrm{~mL}$ of HBS-N buffer to generate a solution $914 \mu \mathrm{M}$ that was further diluted to generate calibration standards, covering the concentration range of $10-1000 \mu \mathrm{M}$. Eleven calibration standards were used to define the calibration curve (10, $100,130,151,230,270,350,402,450,503,950 \mu \mathrm{M})$ that was always obtained the same day as the rest of the other activity measurements. Three quality control (QC) standards $(230,402,503 \mu \mathrm{M})$ were also used for intraday validation showing a $\% \mathrm{CV}<5 \%$.

Aliquots $(7 \mu \mathrm{L})$ of different solutions of P125 in HBS-N buffer were spotted on the surface of the cdMMP-12-modified gold surface, each of them in a

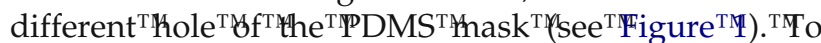
compute the enzyme activity by ESI-MS, $0.5 \mu \mathrm{L}$ of the peptide solutions were sampled from the surface at

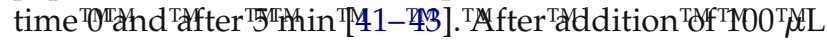
of methanol the resultant solutions were injected into the ESI-MS apparatus for quantitative analysis. Experiments were independently replicated from three to five times.

The P125 peptide was represented in the ESI-MS + ve ion spectra by one peak at $\mathrm{m} / \mathrm{z} 678.7$ (mono-sodiated

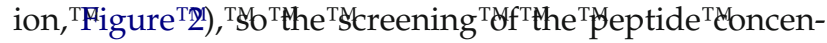
tration was carried out by monitoring the intensity of this peak and all calibration curves showed good linearity $\left(r^{2}>0.98\right)$ over the concentration range. To obtain high-sensitivity spectra, P125 solutions were injected as $25 \mu \mathrm{L}$ aliquots into the ESI-MS apparatus and data were recorded in SIM mode (centre $\mathrm{m} / \mathrm{z} 678.7$ and width $50 \mathrm{Da}$ ).

By setting the base peak at $\mathrm{m} / \mathrm{z} 678.7$ it was possible to obtain an ion chromatogram that presented a shape 
Table 1. Assignment of the peaks generated by HBS-N buffer solution as revealed by ESI-MS (the positive charge is omitted for simplicity). The abundance of peaks is generated because of the formation of $\mathrm{NaCl}$ clusters with the N-(2-Hydroxyethyl)piperazine$\mathrm{N}^{\prime}$-(2-ethanesulfonic acid) and with the sulfonic acid. Isotopic distributions of the peaks with a relative intensity value $>5 \%$ are also reported.

\begin{tabular}{|c|c|}
\hline HBS-N buffer species & Isotopic distribution $(\mathrm{m} / \mathrm{z})$ \\
\hline $\begin{array}{l}\mathrm{SO}_{3} \mathrm{H}\left(\mathrm{NaCl}_{2}\right. \\
\mathrm{HOCH}_{2} \mathrm{CH}_{2} \mathrm{NC}_{4} \mathrm{H}_{8} \mathrm{NC}_{2} \mathrm{H}_{4} \mathrm{SO}_{3} \mathrm{H} \\
\mathrm{SO}_{3} \mathrm{H}\left(\mathrm{NaCl}_{3}\right. \\
\left(\mathrm{HOCH}_{2} \mathrm{CH}_{2} \mathrm{NC}_{4} \mathrm{H}_{8} \mathrm{NC}_{2} \mathrm{H}_{4} \mathrm{SO}_{3} \mathrm{H}\right) \mathrm{Na} \\
\left(\mathrm{HOCH}_{2} \mathrm{CH}_{2} \mathrm{NC}_{4} \mathrm{H}_{8} \mathrm{NC}_{2} \mathrm{H}_{4} \mathrm{SO}_{3}\right) \mathrm{Na}_{2} \\
\mathrm{SO}_{3} \mathrm{H}\left(\mathrm{NaCl}_{4}\right. \\
\left(\mathrm{HOCH}_{2} \mathrm{CH}_{2} \mathrm{NC}_{4} \mathrm{H}_{8} \mathrm{NC}_{2} \mathrm{H}_{4} \mathrm{SO}_{3}\right) \mathrm{Na}_{2}(\mathrm{NaCl}) \\
\mathrm{SO}_{3} \mathrm{H}\left(\mathrm{NaCl}_{5}\right. \\
\left(\mathrm{HOCH}_{2} \mathrm{CH} \mathrm{NC}_{4} \mathrm{H}_{8} \mathrm{NC}_{2} \mathrm{H}_{4} \mathrm{SO}_{3}\right) \mathrm{Na}_{2}(\mathrm{NaCl})_{2} \\
\mathrm{SO}_{3} \mathrm{H}_{2}\left(\mathrm{NaCl}_{6}\right. \\
\left(\mathrm{HOCH}_{2} \mathrm{CH}_{2} \mathrm{NC}_{4} \mathrm{H}_{8} \mathrm{NC}_{2} \mathrm{H}_{4} \mathrm{SO}_{3}\right) \mathrm{Na}_{2}(\mathrm{NaCl})_{3} \\
\mathrm{SO}_{3} \mathrm{H}\left(\mathrm{NaCl}_{7}\right. \\
\left(\mathrm{HOCH}_{2} \mathrm{CH}_{2} \mathrm{NC}_{4} \mathrm{H}_{8} \mathrm{NC}_{2} \mathrm{H}_{4} \mathrm{SO}_{3}\right) \mathrm{Na}_{2}(\mathrm{NaCl})_{4} \\
\mathrm{SO}_{3} \mathrm{H}\left(\mathrm{NaCl}_{8}\right. \\
\left(\mathrm{HOCH}_{2} \mathrm{CH}_{2} \mathrm{NC}_{4} \mathrm{H}_{8} \mathrm{NC}_{2} \mathrm{H}_{4} \mathrm{SO}_{3}\right) \mathrm{Na}_{2}(\mathrm{NaCl})_{5} \\
\mathrm{SO}_{3} \mathrm{H}\left(\mathrm{NaCl}_{9}\right. \\
\left(\mathrm{HOCH}_{2} \mathrm{CH}_{2} \mathrm{NC}_{4} \mathrm{H}_{8} \mathrm{NC}_{2} \mathrm{H}_{4} \mathrm{SO}_{3}\right) \mathrm{Na}_{2}(\mathrm{NaCl})_{6} \\
\mathrm{SO}_{3} \mathrm{H}\left(\mathrm{NaCl}_{10}\right. \\
\left(\mathrm{HOCH}_{2} \mathrm{CH}_{2} \mathrm{NC}_{4} \mathrm{H}_{8} \mathrm{NC}_{2} \mathrm{H}_{4} \mathrm{SO}_{3}\right) \mathrm{Na}_{2}(\mathrm{NaCl})_{7} \\
\mathrm{SO}_{3} \mathrm{H}\left(\mathrm{NaCl}_{11}\right. \\
\left(\mathrm{HOCH}_{2} \mathrm{CH}_{2} \mathrm{NC}_{4} \mathrm{H}_{8} \mathrm{NC}_{2} \mathrm{H}_{4} \mathrm{SO}_{3}\right) \mathrm{Na}_{2}(\mathrm{NaCl})_{8} \\
\mathrm{SO}_{3} \mathrm{H}\left(\mathrm{NaCl}_{12}\right.\end{array}$ & $\begin{array}{l}196.9-198.9-200.9 \\
238.1-239.2 \\
254.9-256.9-259.0 \\
261.3-262.2 \\
283.3-284.2 \\
312.8-314.9-316.8-318.8 \\
341.1-343.2 \\
370.8-372.8-374.8-377 \\
399.0-400.0-401.0-402.0-403.0 \\
428.7-430.7-432.8-434.9-436.7 \\
457.0-457.9-458.9-459.9-460.9-462.9 \\
486.7-488.8-490.7-492.7-494.7 \\
514.9-515.9-517.0-517.9-518.9-519.9-520.9 \\
544.8-546.9-548.8-550.9-552.8-554.8 \\
572.9-573.9-575.0-575.9-576.9-577.9-578.9 \\
602.6-604.6-606.6-608.7-610.6-612.6 \\
630.8-631.8-632.9-633.8-634.8-635.8-636.8-638.8 \\
660.8-662.8-664.8-666.9-668.9-670.8-672.9 \\
688.8-690.8-691.8-692.9-693.9-694.8-695.8-696.8 \\
718.6-720.6-722.6-724.7-726.7-728.7-730.6 \\
746.9-748.9-749.9-750.9-751.9-752.9-753.9-754.9-756.9 \\
777.5-778.6-780.5-782.7-784.5-786.7-788.5\end{array}$ \\
\hline
\end{tabular}

approaching a rectangle, the integral of which was proportional to the concentration of the peptide solution injected. As mentioned in the previous paragraph, P125 solutions were injected into the mass spectrometer after dilution with methanol $(0.5 \mu \mathrm{L}$ of buffered solution in $100 \mu \mathrm{L}$ of methanol). For this reason, four different measurements of $25 \mu \mathrm{L}$ injection of the same P125 solution were possible and the average of these values was taken as the real P125 concentration.

The procedure by which we detect the concentration of P125 solutions in HBS-N buffer by simply adding methanol, without any purification step, gives rise to a

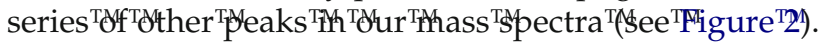
A diffuse attitude for a mass spectrometrist is to think that such added peaks could cause problems by interfering with the molecular peak that has to be monitored. Despite the large amount of literature aimed to find ways of suppressing the peaks coming from the

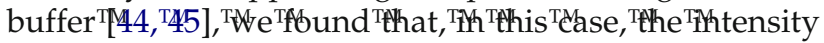
values of the molecular peak at $\mathrm{m} / \mathrm{z} 678.7$ were repeatable as long as the buffer solution always had the same amount of $\mathrm{NaCl}$ dissolved. For this reason we always used the same buffer and particular attention was given to avoid evaporation of the solvent from the solutions. Furthermore, all the series of cluster peaks in the recorded $^{\mathrm{TM} E S I-M S^{\mathrm{TM}} \text { spectra }}{ }^{\mathrm{TM}}$ were $^{\mathrm{TM}}$ assigned ${ }^{\mathrm{TM}}\left(\mathrm{Table}^{\mathrm{TM}}\right.$; MS/MS investigations were in some cases carried out, data not shown), so that it was possible to identify also those peaks at $\mathrm{m} / \mathrm{z} 360.4$ and $\mathrm{m} / \mathrm{z} 408.4$ correspondent to the peptide fragments generated by the action of

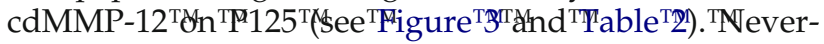
theless, monitoring the decrease in the intensity of the molecular peak at $\mathrm{m} / \mathrm{z} 678.7$ was preferred for the enzyme activity measurements to the increase of the intensity of the peaks generated by the peptide fragments because the latter did not follow a linear intensity trend. The different trend was probably attributable to

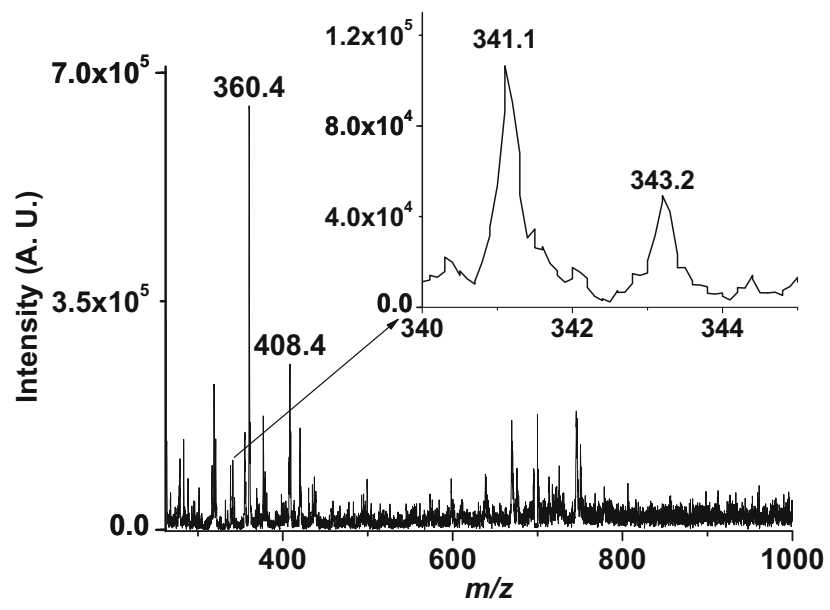

Figure 3. ESI-MS spectrum of P125 in HBS-N buffer in the presence of cdMMP-12. The peak at $\mathrm{m} / \mathrm{z} 678.7$ attributed to the monosodiated ion species is no longer visible, whereas new peaks assigned to the P125 fragments appear in the spectrum (see text for their assignment). Because of the high amount of cluster peaks appearing in the mass range $\mathrm{m} / \mathrm{z} 200-400$, the kinetics measurements were carried out by following the decrease of the peak at $\mathrm{m} / \mathrm{z} 678.7$ as discussed in the text. In the insert an example of the isotopic distribution for the low-intensity cluster peaks assigned to the $\left(\mathrm{HOCH}_{2} \mathrm{CH}_{2} \mathrm{NC}_{4} \mathrm{H}_{8} \mathrm{NC}_{2} \mathrm{H}_{4} \mathrm{SO}_{3}\right) \mathrm{Na}_{2}(\mathrm{NaCl})$ species is also reported. 
Table 2. Peptide fragments generated by interaction of P125 with cdMMP-12 in HBS-N buffer

\begin{tabular}{|c|c|c|}
\hline P125 fragment ${ }^{a}$ & Expected $\mathrm{m} / \mathrm{z}$ & Experimental $\mathrm{m} / \mathrm{z}$ \\
\hline $\begin{array}{l}\mathrm{HSSCH}_{2} \mathrm{CHC}_{4} \mathrm{H}_{9} \mathrm{CONHCH}_{2} \mathrm{COOC}_{2} \mathrm{H}_{5} \mathrm{Na}_{2} \mathrm{Cl} \\
\mathrm{CH}_{3} \text { CO-Pro-Leu-Gly-OH Na}{ }_{2} \mathrm{Cl}\end{array}$ & $\begin{array}{l}360.0 \\
408.1\end{array}$ & $\begin{array}{l}360.4 \\
408.4\end{array}$ \\
\hline
\end{tabular}

${ }^{a}$ Assignment confirmed by MS-MS experiments.

interference with buffer- and salt-generated ionic species mentioned above, which are numerous in the peptide fragments mass range $(\mathrm{m} / \mathrm{z} 200-400)$. It is worthwhile to note that these considerations represent a further proof of the utility of the ESI-MS approach to the study of ion cluster formation, as it is copiously reported ${ }^{\mathrm{T}}\left[46^{\mathrm{Tu}} \mathrm{m} 8\right]$.

MS/MS scans were acquired using an isolation width of $5 \mathrm{~m} / \mathrm{z}$, activation $\mathrm{q}_{\mathrm{z}}$ of 0.250 , activation time of $30 \mathrm{~ms}$, and normalized collision energy (NCE) in the range $30-40 \%$, dependent on the ion. [NCE is the amplitude of the resonance excitation RF voltage scaled to the precursor mass based on the formula: RF amplitude $=\{\mathrm{NCE} \% / 30 \%\}$ (precursor ion mass $\times$ tick amp slope + tick amp intercept), where the tick amp slope and tick amp intercept are instrument specific values. For our LCQ Deca, 35\% NCE for $\mathrm{m} / \mathrm{z} 1000=1.8 \mathrm{~V}$.]

\section{Results and Discussion}

It is known that a critical aspect of solid-state MMPs activity assay is represented by the proper preparation

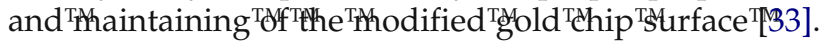
A too-dense packing of the anchored MMPs affects the enzyme activity whereas lower surface coverage is not suitable for reliable ESI-MS detection. The negative influence of higher surface packing of uninhibited MMPs can be attributed to the autolytic cleavage of the

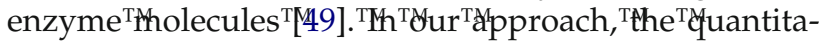
tive responses of the FT-SPR shift with solutions having a known concentration of cdMMP-12 (data not shown) were used to find that a surface coverage of $4.2 \times 10^{13}$ molecules $/ \mathrm{cm}^{2}$ was adequate for an ESI-MS kinetics assay of cdMMP-12 anchored and freeze-dried on gold chips.

The + ve ion ESI-MS spectrum of the P125 substrate peptide $(\mathrm{MW}=655 \mathrm{Da})$ showed a peak at $\mathrm{m} / \mathrm{z} 678.7$ attributed to the mono-sodiated $[\mathrm{P} 125+\mathrm{Na}]^{+}$species

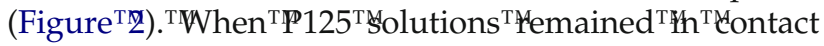
with the cdMMP-12 anchored onto the gold chip surfaces new species were generated. The cdMMP-12

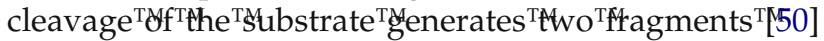

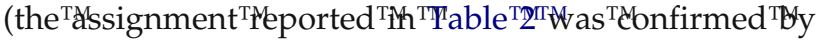
MS-MS experiments) detectable by ESI-MS at $\mathrm{m} / \mathrm{z} 360.4$

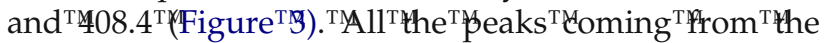
HBS-N buffer are around the 200- to 500-Da range and

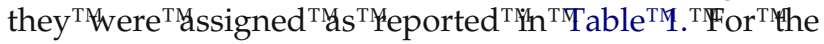
reasons mentioned in the previous section, ESI-MS data for the quantitative evaluation of the progressing of the cdMMP-12/substrate reaction were obtained by monitoring the decrease in the $\mathrm{m} / \mathrm{z} 678.7$ peak intensity.
The calibration curve generated from standard solutions (see the previous section) allowed us to convert the $\mathrm{m} / \mathrm{z} 678.7$ peak intensity values into peptide concentration ([P125]) of the different aliquot samples.

Preliminary experiments were conducted to obtain a representative progress curve to be used to determine the optimum enzyme concentration and reaction

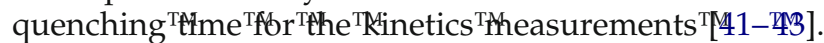
The curve were obtained by plotting the amount of cleaved P125 versus time when $25 \mu \mathrm{L}$ aliquots having three representative concentrations of P125 (100, 250, $400 \mu \mathrm{M})$ in HBS-N buffer were put in contact with the cdMMP-12 modified sensor chip surface, and $0.5 \mu \mathrm{L}$ aliquots were sampled every minute. Every aliquot was then added with $100 \mu \mathrm{L}$ of methanol and $25 \mu \mathrm{L}$ of the resultant solution was injected into the ESI-MS apparatus. This large dilution of the original aliquots was found to be necessary to avoid capillary obstruction and high spray current values. The $25 \mu \mathrm{L}$ volume of the initial solutions spotted onto the gold surface arrayed with the PDMS mask was chosen to allow the multiple sampling from the same peptide solution, a necessary step for the construction of a progress curve. The working volume could then be lowered to $7 \mu \mathrm{L}$ when only two sampling operations had to be carried out (at 0 and $5 \mathrm{~min}$; see below) for the kinetics measurements.

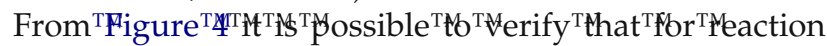

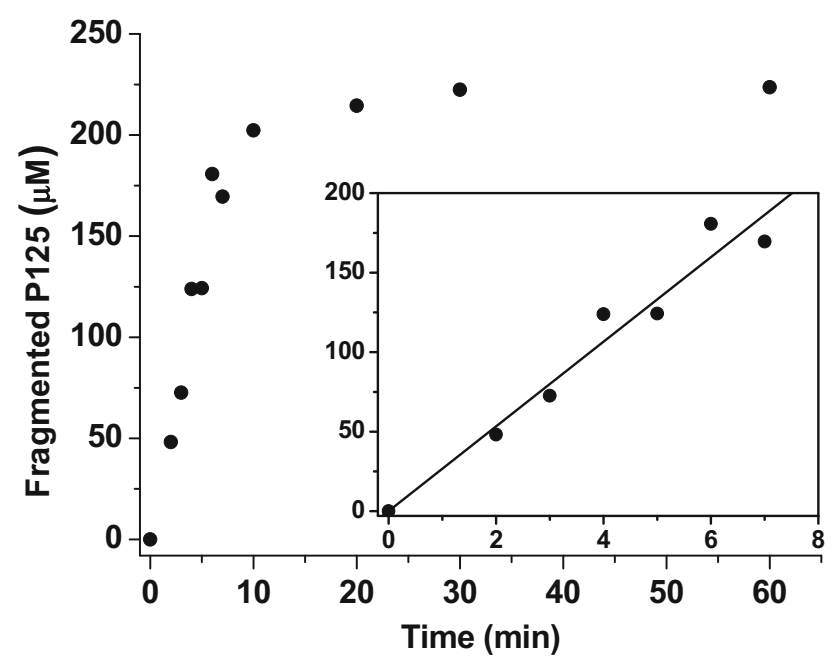

Figure 4. The decrease of the initial concentration of P125 (250 $\mu \mathrm{M}$ was the initial concentration in this graph) is used to calculate the increased amount of P125 cleaved by cdMMP-12. The cdMMP-12 activity was so monitored and it is possible to see that for this concentration and for time $<8 \mathrm{~min}$ the curve can be approximated to a straight line (see insert). 


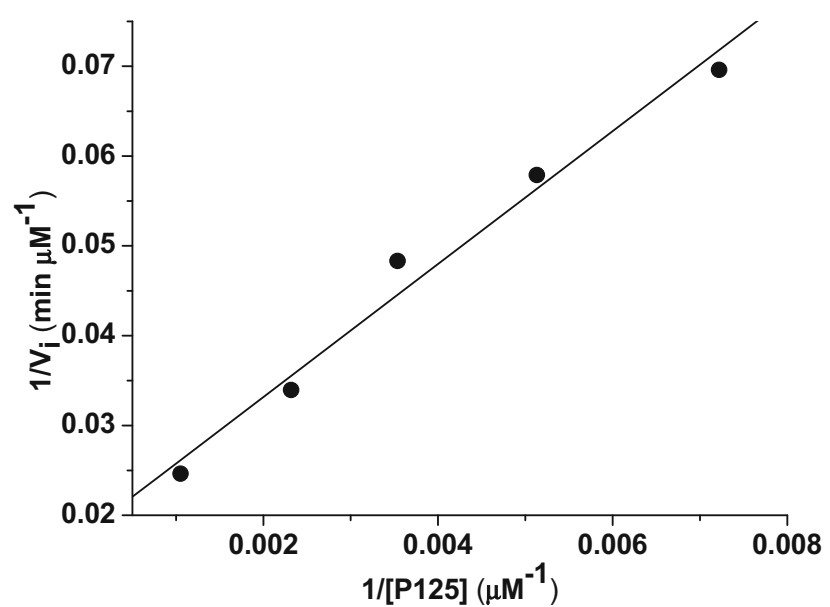

Figure 5. Lineweaver-Burk plot for cdMMP-12/P125 $\left(r^{2}=0.98\right)$ at room temperature. Five P125 solutions at different concentrations were spotted on different holes of the PDMS mask and the fragmentation of P125 by immobilized cdMMP-12 was monitored by ESI-MS, as explained in the text.

time $<8$ min the curve obtained can be approximated to a straight line. An optimal reaction time of $5 \mathrm{~min}$ was determined with a substrate conversion of roughly $55 \%$. Because the chosen optimal reaction time resided in the linear region of the progression curve, the initial velocity $\left(\mathrm{V}_{\mathrm{i}}\right)$ was simply calculated by dividing the difference between the ESI-MS determined P125 amounts at $t=0$ min and $t=5 \mathrm{~min}$ by the reaction time.

It was previously demonstrated that MMPs follow a Michaelis-Menten ${ }^{\mathrm{T}}$ Kinetics $^{\mathrm{T}}[51]{ }^{\mathrm{T}}{ }^{\mathrm{S}} \mathrm{So}^{\mathrm{T}}$ the ${ }^{\mathrm{T}} \mathrm{K}_{\mathrm{M}}$ and $\mathrm{V}_{\max }$ values can be estimated from the double-reciprocal plot of $1 / V_{i}$ versus $1 /$ [P125]. In particular, to determine $K_{M}$ and $\mathrm{V}_{\max }, 7 \mu \mathrm{L}$ aliquots having five different concentrations of P125 (138.5, 195.0, 282.4, 431.0, $952.4 \mu \mathrm{M})$ in HBS-N buffer were put in contact with the cdMMP-12 freeze-dried chip surface, each of them in a different hole of the PDMS mask, and $0.5 \mu \mathrm{L}$ aliquots were sampled at time $t=0 \mathrm{~min}$ and after $5 \mathrm{~min}$.

A representative Lineweaver-Burk plot for the reaction between the P125 and the cdMMP-12 immobilized

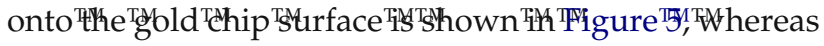

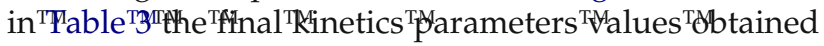
are reported. It can be seen that the $\mathrm{K}_{\mathrm{M}}$ and $\mathrm{V}_{\max }$ values obtained for cdMMP-12 immobilized on Au (111) and

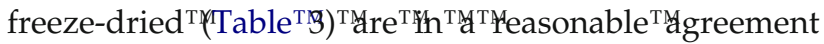
with values reported for the interaction between MMP-12 and the P125 substrate interaction in solution

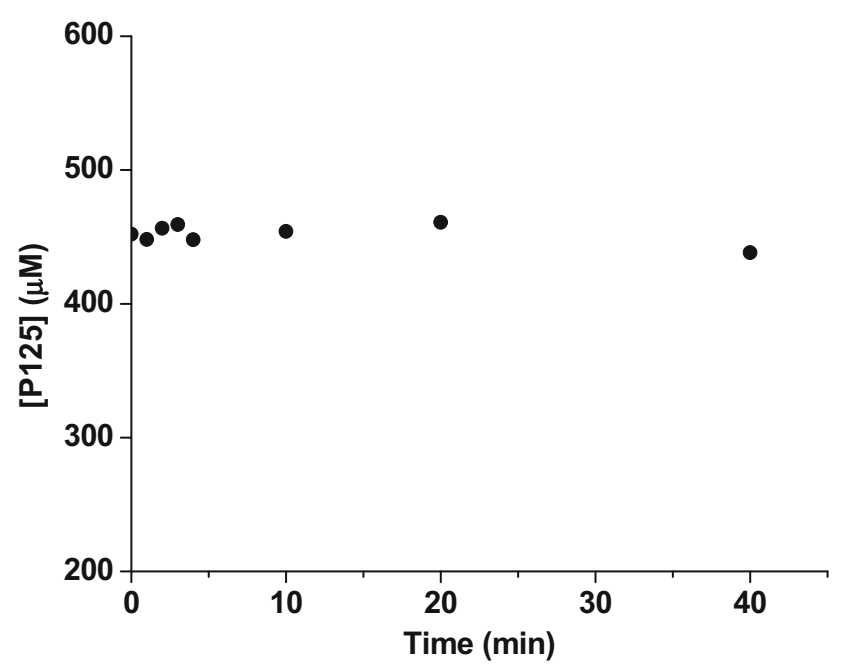

Figure 6. cdMMP-12 interaction with P125 after inhibition with NNGH. In this case, the P125 initial concentration was $450 \mu \mathrm{M}$ and it did not change appreciably with time, as it was revealed by the absence of a decrease with time in the P125 molecular peak intensity at $\mathrm{m} / \mathrm{z}$ 678.7. The immobilized and freeze-dried cdMMP-12 was totally inhibited by NNGH and was not active in this case.

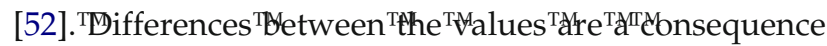
of the higher number of enzyme molecules per substrate molecules required for the proposed ESI-MS activity assay compared to the usual enzyme/substrate ratio used in spectrophotometric methods. It is also worthwhile to note that only the catalytic domain of the MMP-12 is here under study.

The advantages offered by the freeze-drying procedure can be evaluated by comparing the above-presented results with those obtained by replicating the above-described procedure without the freeze-drying step. The average $K_{M}$ and $V_{\max }$ values obtained in this case $\left(\mathrm{K}_{\mathrm{M}}=2332 \pm 1537 \mu \mathrm{M}\right.$ and $\mathrm{V}_{\max }=15 \pm 10 \mathrm{pmol}$ $\mathrm{s}^{-1)}$ differ significantly from the reference values. Moreover, independently replicated experiments produced more scattered data $(\% \mathrm{CV}=65 \%)$ with respect to the freeze-drying procedure $(\% \mathrm{CV}=20 \%)$.

The same experimental procedure was carried out also after inhibition of cdMMP-12 by NNGH inhibitor. A lack of activity by cdMMP-12 with P125 was ob-

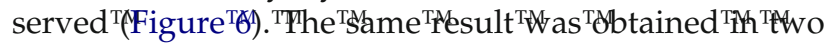
different cases, where cdMMP-12 incubation with NNGH was carried out before or after the enzyme immobilization.

Table 3. Kinetic parameters for cdMMP-12 obtained by following the two procedures described in the text

\begin{tabular}{lccr}
\hline \multicolumn{1}{c}{ Parameter $^{\mathrm{a}}$} & cdMMP-12 immobilized & \multicolumn{2}{c}{ cdMMP-12 immobilized } \\
on Au (111) & on Au (11) and freeze-dried & Literature $^{\text {b }}$ \\
\hline \hline $\mathrm{K}_{\mathrm{M}}(\mu \mathrm{M})$ & $2332 \pm 1537$ & $456 \pm 36$ & 110 \\
$\mathrm{~V}_{\text {max }}\left(\mathrm{pmol} \mathrm{s}{ }^{-1}\right)$ & $15 \pm 10$ & $4.55 \pm 0.98$ & 2.37 \\
\hline
\end{tabular}

It is possible to note that the dispersion of the data is smaller for the cdMMP-12 freeze-dried on the surface, proving a higher repeatability in this case.

aThe spreading of the data is represented by the sample standard deviation ( \pm SD).

${ }^{\mathrm{b}}$ From http://www.biomol.com/SiteData/docs/productdata/ak402.pdf [52]. Data obtained from MMP-12 by using a colorimetric method. 
It is also worth noting that the proposed approach offers the possibility of evaluating the $\mathrm{k}_{\text {cat }}$ parameter. This last parameter takes into account the enzyme concentration $\left(\mathrm{k}_{\mathrm{cat}}=\mathrm{V}_{\max } / \mathrm{E}_{\mathrm{T}}\right.$, where $\mathrm{E}_{\mathrm{T}}$ is the enzyme concentration) and it is possible to note that the $\mathrm{k}_{\text {cat }}=$ $2.2 \pm 0.6 \mathrm{~s}^{-1}$ value obtained from our experiments is

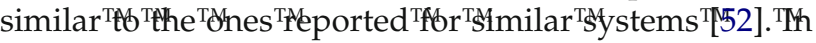
our case, $\mathrm{E}_{\mathrm{T}}$ was estimated to be about $300 \mathrm{nM}$ by considering the surface coverage measured by FT-SPR $\left(4.2 \times 10^{13}\right.$ molecules $\left./ \mathrm{cm}^{2}\right)$, the area of the hole containing the peptide solution $\left(3 \mathrm{~mm}^{2}\right)$, and the volume of the drop in contact with the surface $(7 \mu \mathrm{L})$.

\section{Conclusions}

A new methodology for activity measurements of MMPs anchored on solid support was developed. The new approach can be particularly useful in the search for new inhibitors of MMPs and, because of the anchoring of the enzyme molecules instead of the possible inhibitors, the method is very compatible with a variety of high-throughput screening methods. Specifically, the presented results demonstrate the possibility of monitoring cdMMP-12 inhibition on solid-state support. By coupling the FT-SPR and ESI-MS techniques a comprehensive study of the kinetic of inhibition and the possibility to determine the activity of MMPs is shown to be feasible.

The possibility of detecting peptide molecules in their own buffer, skipping all the extraction steps, was proved and we managed to assign all the peaks produced by the HBS-N buffer in ESI-MS, demonstrating once again the possibility of studying metal ion clusters by ESI-MS.

\section{Acknowledgments}

The authors thank MIUR (FIRB RBNE01TTJW_004, RBNE03PX83, RBIN04L28Y, and PRIN 2005 n 2005038704_004) for financial support.

\section{References}

1. Reymond, J. L., Ed. Enzyme Assays: High-throughput Screening, Genetic Selection and Fingerprinting; Wiley-VCH: New York; 2006.

2. Min, D.-H.; Tang, W.-J.; Mrksich, M. Chemical Screening by Mass Spectrometry to Identify Inhibitors of Anthrax Lethal Factor. Nat. Biotechnol. 2004, 22, 717-723.

3. Su, J.; Bringer, M. R.; Ismagilov, R. F.; Mrksich, M. Combining Microfluidic Networks and Peptide Arrays for Multi-enzyme Assays. J. Am. Chem. Soc. 2005, 127, 7280-7281.

4. Min, D. H.; Yeo, W. S.; Mrksich, M. A Method for Connecting Solutionphase Enzyme Activity Assays with Immobilized Format Analysis by Mass Spectrometry. Anal. Chem. 2004, 76, 3923-3929.

5. Shen, Z.; Go, E. P.; Gamez, A.; Apon, J. V.; Fokin, V.; Greig, M.; Ventura, M.; Crowell, J. E.; Blixt, O.; Paulson, J. C.; Stevens, R. C.; Finn, M. G.; Siuzdak, G. A Mass Spectrometry Plate Reader: Monitoring Enzyme Activity and Inhibition with a Desorption/Ionization on Silicon (DIOS) Platform. Chem. Biol. Chem. 2004, 5, 921-927.

6. Min, D.; Mrksich, M. Profiling Kinase Activities by Using a Peptide Chip and Mass Spectrometry. Angew. Chem. Int. Ed. 2004, 43, 5973-5977.

7. Babiak, P.; Reymond, J. A High-throughput, Low-volume Enzyme Assay on Solid Support. Anal. Chem. 2005, 77, 373-377.

8. Huber, W.; Hoffman, F. A New Strategy for Improved Secondary Screening and Lead Optimization Using High-resolution SPR Characterization of Compound-Target Interactions. J. Mol. Recogn. 2005, 18, 273-281.
9. Nedelkov, D.; Nelson, R. W. Surface Plasmon Resonance Mass Spectrometry for Protein Analysis. Methods Mol. Biol. 2006, 328, $131-$ 139.

10. Nedelkov, D.; Nelson, R. W. Surface Plasmon Resonance Mass Spectrometry: Recent Progress and Outlooks. Trends Biotechnol. 2003, 21, 301-305.

11. Borch, J.; Roepstorff, P. Screening for Enzyme Inhibitors by Surface Plasmon Resonance Combined with Mass Spectrometry. Anal. Chem. 2004, 76, 5243-5248.

12. Massova, I.; Kotra, L. P.; Fridman, R.; Mobashery, S. Matrix Metalloproteinases: Structures, Evolution, and Diversification. FASEB J. 1998, 12, 1075-1095.

13. Coussens, L. M.; Werb, Z. Matrix Metalloproteinases and the Development of Cancer. Chem. Biol. 1996, 3, 895-904.

14. Ramsey, K. H.; Sigar, I. M.; Schripsema, J. H.; Shaba, N.; Cohoon, K. P. Expression of Matrix Metalloproteinases Subsequent to Urogenita Chlamydia muridarum Infection of Mice. Infect. Immun. 2005, 73, 6962-6973.

15. Koivunen, E.; Arap, W.; Valtanen, H.; Rainisalo, A.; Medina, O. P.; Heikkilä, P.; Kantor, C.; Gahmberg, C. G.; Salo, T.; Konttinen, Y. T.; Sorsa, T.; Ruoslahti, E.; Pasqualini, R. Tumor Targeting with a Selective Gelatinase Inhibitor. Nat. Biotechnol. 1999, 17, 768-774.

16. Farkas, E.; Katz, Y.; Bhusare, S.; Reich, R.; Röschenthaler, G.; Königsmann, M.; Breuer, E. Carbamoylphosphonate-based Matrix Metalloproteinase (MMP) Inhibitor Metal Complexes-Solution Studies and Stability Constants. Towards a Zinc-selective Binding Group. J. Biol. Inorg. Chem. 2004, 9, 307-315

17. Dublanchet, A.; Ducrot, P.; Andrianjara, C.; O'Gara, M.; Morales, R.; Compere, D.; Denis, A.; Blais, S.; Cluzeau, P.; Courte, K.; Hamon, J. Moreau, F.; Prunet, M.; Tertre, A. Structure-based Design and Synthesis of Novel Non-zinc Chelating MMP-12 Inhibitors. Bioorg. Med. Chem. Lett. 2005, 15, 3787-3790.

18. Dive, V.; Andarawewa, K. L.; Boulay, A.; Matziari, M.; Beau, F.; Guerin, E.; Rousseau, B.; Yiotakis, A.; Rio, M. Dosing and Scheduling Influence the Antitumor Efficacy of a Phosphinic Peptide Inhibitor of Matrix Metalloproteinases. Int. J. Cancer 2005, 113, 775-781.

19. Weingarten, H.; Feder, J. Spectrophotometric Assay for Vertebrate Collagenase. Anal. Biochem. 1985, 147, 437-440.

20. Beekman, B.; Drijfhout, J. W.; Bloemhoff, W.; Ronday, H. K.; Tak, P. P Koppele, J. M. Convenient Fluorometric Assay for Matrix Metalloproteinase Activity and Its Application in Biological Media. FEBS Lett. 1996 390, 221-225.

21. Liu, Y.; Kati, W : Chen, C.; Tripathy, R.; Molla, A.; Kohlbreuner, W. Use of a Fluorescence Plate Reader for Measuring Kinetic Parameters with Inner Filter Effect Correction. Anal. Biochem. 1999, 267, 331335.

22. Lauer-Fields, J. L.; Nagase, H.; Fields, G. B. Development of a Solidphase Assay for Analysis of Matrix Metalloproteinase Activity. J. Biomol. Technol. 2004, 15, 305-316.

23. Didraga, M.; Barroso, B.; Bischoff, R. Recent Developments in Proteoglycan Purification and Analysis. Curr. Pharm. Anal. 2006, 2, 323-337.

24. Banci, L.; Bertini, I.; Calderone, V.; Ciofi-Baffoni, S.; Mangani, S.; Martinelli, M.; Palumaa, P.; Wang, S. A Hint for the Function of Human Sco1 from Different Structures. Proc. Natl. Acad. Sci. U.S.A. 2006, 103, 8595-8600.

25. Devreese, B.; Van Beeumen, J. The Important Contribution of High Precision Mass Spectrometric Methods in the Study of the StructureFunction Relationship of Proteins and Enzymes. Analyst 1998, 123, 2457-2461.

26. Bothner, B.; Chavez, R.; Wei, J.; Strupp, C.; Phung, O.; Schneemann, A. Siuzdak, G. Monitoring Enzyme Catalysis with Mass Spectrometry. J. Biol. Chem. 2000, 275, 13455-13459.

27. Somsen, G. W.; Mol, R.; de Jong, G. J. On-line Micellar Electrokinetic Chromatography-Mass Spectrometry: Feasibility of Direct Introduction of Non-volatile Buffer and Surfactant into the Electrospray Interface. J. Chromatogr. A 2003, 1000, 953-961.

28. Ong, S.; Mann, M. Mass-spectrometry Based Proteomics Turns Quantitative. Nat. Chem. Biol. 2005, 1, 252-262.

29. Su, J.; Mrksich, M. Using Mass Spectrometry to Characterize Selfassembled Monolayers Presenting Peptides, Proteins, and Carbohydrates. Angew. Chem. Int. Ed. 2002, 41, 4715-4718.

30. Nedelkov, D.; Nelson, R. W. Analysis of Native Proteins from Biologica Fluids by Biomolecular Interaction Analysis Mass Spectrometry (BIA/ MS): Exploring the Limit of Detection, Identification of Non-specific Binding and Detection of Multi-protein Complexes. Biosensors Bioelectr. 2001, 16, 1071-1078.

31. Olson, M. W.; Gervasi, D. C.; Mobashery, S.; Fridman, R. Kinetic Analysis of the Binding of Human Matrix Metalloproteinase-2 and -9 to Tissue Inhibitor of Metalloproteinase (TIMP)-1 and TIMP-2. J. Biol. Chem. 1997, 272, 29975-29983.

32. Pieper-Fürst, U.; Kleuser, U.; Stöcklein, W. F. M.; Warsinke, A.; Scheller, F. W. Detection of Subpicomolar Concentrations of Human Matrix Metalloproteinase-2 by an Optical Biosensor. Anal. Biochem. 2004, 332, $160-167$.

33. Grasso, G.; D'Agata, R.; Rizzarelli, E.; Spoto, G.; Picardi, A.; Romanelli, A.; Fragai, M.; Yeo, K. J. Activity of Anchored Human Matrix Metalloproteinase-1 Catalytic Domain on Au (111) Surfaces Monitored by ESI-MS. J. Mass Spectrom. 2005, 40, 1565-1571. 
34. Grasso, G.; Fragai, M.; Rizzarelli, E.; Spoto, G.; Kwon, J. Y. In Situ AP/MALDI-MS Characterization of Anchored Matrix Metalloproteinases. J. Mass Spectrom. 2006, 41, 1561-1569.

35. Weingarten, H.; Martin, R.; Feder, J. Synthetic Substrates of Vertebrate Collagenase. Biochemistry 1985, 24, 6730-6734

36. MacPherson, L. J.; Bayburt, E. K.; Capparelli, M. P.; Carroll, B. J.; Goldstein, R.; Justice, M. R.; Zhu, L.; Hu, S.; Melton, R. A.; Fryer, L.; Goldberg, R. L.; Doughty, J. R.; Spirito, S.; Blancuzzi, V.; Wilson, D.; O’Byrne, E. M.; Ganu, V.; Parker, D. T. Discovery of CGS 27023A, a Non-peptidic, Potent, and Orally Active Stromelysin Inhibitor That Blocks Cartilage Degradation in Rabbits. J. Med. Chem. 1997, 40, 25252532.

37. Lide, D. R. Handbook of Chemistry and Physics, 71st ed. CRC Press: Boston; 1990.

38. Jung, L. S.; Campbell, C. T.; Chinowsky, T. M.; Mar, M. N.; Yee, S. S. Quantitative Interpretation of the Response of Surface Plasmon Resonance Sensors to Adsorbed Films. Langmuir 1998, 14, 5636-5648.

39. Wang, X.; Sakuma, T.; Asafu-Adjaye, E.; Shiu, G. K. Determination of Ginsenosides in Plant Extracts from Panax ginseng and Panax quinquefolius L. by LC/MS/MS. Anal. Chem. 1999, 71, 1579-1584.

40. Mauri, P.; Migliazza, B.; Pietta, P. Liquid Chromatography/Electrospray Mass Spectrometry of Bioactive Terpenoids in Ginkgo biloba L. J. Mass Spectrom. 1999, 34, 1361-1367.

41. Pi, N.; Leary, J. A. Determination of Enzyme/Substrate Specificity Constants Using a Multiple Substrate ESI-MS Assay. J. Am. Soc. Mass Spectrom. 2004, 15, 233-243.

42. Gao, H.; Leary, J. A. Multiplex Inhibitor Screening and Kinetic Constant Determinations for Yeast Hexokinase Using Mass Spectrometry Based Assays. J. Am. Soc. Mass Spectrom. 2003, 14, 173-181.

43. Pi, N.; Armstrong, J. I.; Bertozzi, C. R.; Leary, J. A. Kinetic Analysis of NodST Sulfotransferase Using an Electrospray Ionization Mass Spectrometry Assay. Biochemistry 2002, 41, 13283-13288.
44. Iavarone, A. T.; Udekwu, O. A.; Williams, E. R. Buffer Loading for Counteracting Metal Salt-induced Signal Suppression in Electrospray Ionization. Anal. Chem. 2004, 76, 3944-3950.

45. Wang, G.; Cole, R. B. Solvation Energy and Gas-phase Stability Influences on Alkali Metal Cluster Ion Formation in Electrospray Ionization Mass Spectrometry. Anal. Chem. 1998, 70, 873-881.

46. Blades, A. T.; Peschke, M.; Verkerk, U. H.; Kebarle, P. Hydration Energies in the Gas Phase of Select $(\mathrm{MX})_{m} \mathrm{M}^{+}$Ions, Where $\mathrm{M}^{+}=\mathrm{Na}^{+}$ $\mathrm{K}^{+}, \mathrm{Rb}^{+}, \mathrm{Cs}^{+}, \mathrm{NH}_{4}^{+}$and $\mathrm{X}^{-}=\mathrm{F}^{-}, \mathrm{Cl}^{-}, \mathrm{Br}^{-}, \mathrm{I}^{-}, \mathrm{NO}_{2}{ }^{-}, \mathrm{NO}_{3}^{-}$. Observed Magic Numbers of $(\mathrm{MX})_{m} \mathrm{M}^{+}$Ions and Their Possible Significance. J. Am. Chem. Soc. 2004, 126, 11995-12003.

47. Hao, C.; March, R. E.; Croley, T. R.; Smith, J. C.; Rafferty, S. P. Electrospray Ionization Tandem Mass Spectrometric Study of Salt Cluster Ions. Part 1-Investigations of Alkali Metal Chloride and Sodium Salt Cluster Ions. J. Mass Spectrom. 2001, 36, 79-96.

48. Zhang, D.; Cooks, R. G. Doubly Charged Ions $\left[(\mathrm{NaCl})_{m}(\mathrm{Na})_{2}\right]^{2+}$ : Magic Numbers, Dissociation, and Structure. Int. J. Mass Spectrom. 2000 195/196, 667-684.

49. Clark, I. M.; Mitchell, R. E.; Powell, L. K.; Bigg, H. F.; Cawston, T. E. O'Hare, M. C. Recombinant Porcine Collagenase: Purification and Autolysis. Arch. Biochem. Biophys. 1995, 316, 123-127.

50. Neumann, U.; Kubota, H.; Frei, K.; Ganu, V.; Leppert, D. Characterization of Mca-Lys-Pro-Leu-Gly-Leu-Dppa-Ala-Arg- $\mathrm{NH}_{2}$, a Fluorogenic Substrate with Increased Specificity Constants for Collagenases and Tumor Necrosis Factor Converting Enzyme. Anal. Biochem. 2004, 328, 166-173.

51. Nagase, H.; Fields, C. G.; Fields, G. B. Design and Characterization of a Fluorogenic Substrate Selectively Hydrolyzed by Stromelysin 1 (Matrix Metalloproteinase-3). J. Biol. Chem. 1994, 269, 20952-20957.

52. ${ }^{\mathrm{T} h t t p: / / w w w . b i o m o l . c o m / S i t e D a t a / d o c s / p r o d u c t d a t a / a k 402 . p d f ~}{ }^{\mathrm{TM}}$ (accessed February 2007). 